\title{
Effect of Water Depths on the Hydrodynamic Responses of an FPSO Platform
}

\author{
Matthew Guan ${ }^{1, *}$, Montasir Osman Ahmed $\mathrm{Ali}^{1}$, and Cheng Yee $\mathrm{Ng}^{1}$ \\ ${ }^{1}$ Civil and Environmental Engineering Department, Universiti Teknologi PETRONAS, 32610 Bandar \\ Seri Iskandar, Perak, Malaysia
}

\begin{abstract}
Ship-shaped Floating Production Storage Offloading platforms (FPSO) are commonly used in the production of oil and gas in offshore deepwater regions. The vessel is held in place by mooring lines anchored to the seabed during operation, either in spread or turret mooring arrangement. When designing such systems, water depth is a main factor that needs to be considered. At greater depths, the hydrodynamic properties of mooring lines become important and may not be accurately predicted through traditional experiments or numerical quasi-static models. Numerical simulation using coupled dynamic analysis is thus recommended, as the hull-mooring behaviour is analysed simultaneously, and the damping and added mass properties of the entire mooring line system is taken into account. This paper investigates the motions and mooring line tensions of a turret-moored FPSO at various water depths ranging from $1000 \mathrm{~m}$ to $2000 \mathrm{~m}$. The analysis focuses on numerical simulations in the fully coupled dynamic time domain. The study utilizes the commercial software AQWA, with the FPSO model subjected to a unidirectional random wave condition. The hull hydrodynamics is first solved using the 3D radiation/diffraction panel method, and the hull response equation is then coupled with the mooring line equation. The dynamic motions and mooring line tensions results are presented in terms of statistical parameters as well as response spectrum. The results highlight the significance of greater water depths on low frequency responses in surge motions and mooring line tensions, and provides insight on the increasing and decreasing trend of these responses.
\end{abstract}

\section{Introduction}

In recent years, the offshore industry has seen an increased interest in the development of deep and ultra-deepwater fields. Floating platforms are the most viable option in these areas. The vessels generally utilise a system of mooring lines anchored to the seabed to keep the platform in place.

In shallow waters, the effects of mooring line damping due to environmental forces are relatively small. Such systems may be satisfactorily predicted via computationally inexpensive quasi-static uncoupled analysis, or physical testing of a full-scale model.

\footnotetext{
*Corresponding author: matthewgzh@gmail.com
} 
At greater depths however, the mooring lines significantly affect the behavior of the system. Traditional and simplified methods used for predicting shallow water systems may thus be unfeasible or yield inaccurate results [1-4]. Therefore, it is important to incorporate the dynamics of the mooring lines in the analysis and design procedure. The coupled dynamic analysis is thus recommended and applied for a rigorous and accurate estimations of deepwater systems. Research have shown that the mooring line damping significantly affects the low frequency motions and mooring line tensions of an FPSO [5, 6].

This study further explores the influence of water depth on a floating platform and its mooring system. A shipped-shaped turret-moored FPSO is taken as a case study. The fully coupled dynamic analysis method is employed, concentrating on water depths between $1000-2000 \mathrm{~m}$. Prior to this, the numerical model has been validated against published results [7].

\section{Methodology}

\subsection{Dynamics of a floating system}

In analyzing the mooring lines, assuming no torque or twisting moment, the linear momentum conservation equation can be represented with respect to a position vector $\vec{r}=$ $(s, t)$, in which $s=$ arc length and $t=$ time:

$$
\begin{gathered}
-\left(B \vec{r}^{\prime \prime}\right)^{\prime \prime}+\left(\lambda \vec{r}^{\prime}\right)^{\prime}+\vec{q}=m \ddot{\vec{r}} \\
\lambda=T-B \kappa^{2}
\end{gathered}
$$

The primes and dots are the spatial s-derivative and time derivative respectively; $B=$ bending stiffness, $T=$ local effective tension, $\kappa=$ local curvature, $m=$ mass per unit length, $\vec{q}=$ distributed force on the rod per unit length, and $\lambda=$ Lagrange multiplier.

Assuming the rod is elastic and extensible:

$$
\frac{1}{2}(\vec{r} \cdot \vec{r}-1)=\frac{T}{A_{t} E} \approx \frac{\lambda}{A_{t} E}
$$

Where $E=$ Young's modulus, $A_{t}=A_{e}-A_{i}$ (outer - inner cross-sectional area).

The generalized Morison equation is used to define the normal component of the distributed external force on the rod per unit length, given as:

$$
q_{n}=\rho C_{I} A_{e} \dot{v}_{n}+\rho C_{D} \frac{D}{2}\left|v_{n r}\right| v_{n r}+\rho C_{m} A_{e}\left|\ddot{r}_{n}\right|
$$

$C_{I}, C_{D}$ and $C_{m}$ are the inertia, drag and added mass coefficients respectively; $v_{n r}, \dot{v}_{n}$ and $\ddot{r}_{n}$ are normal relative velocity, normal fluid acceleration and normal structure acceleration respectively; $\rho=$ fluid density and $D=$ local diameter. The rod's effective weight (net buoyancy) should also be included in $q_{n}$ as a static load.

The cable dynamics is solved by discretizing the length of the cable into a number of finite elements. The equation is then combined with the hull response to compute the time domain equation of motion:

$$
\left[M+M_{a}(\infty)\right] \ddot{u}_{p}+\int_{0}^{\infty} R(t-\tau) \dot{u}_{p} \mathrm{~d} \tau+K_{H} u_{p}=F_{D}+F^{(1)}+F^{(2)}+F_{p}+F_{w}+F_{c}+F_{W D}
$$


where $\widetilde{M}$ and $\widetilde{M}_{a}$ are the mass and added mass matrix respectively, $\tilde{R}=$ retardation function matrix, $\widetilde{K}_{H}=$ hydrostatic restoring coefficient, $\widetilde{F}_{D}=$ drag force matrix on the hull, $\tilde{F}^{(1)}$ and $\tilde{F}^{(2)}=1^{\text {st }}$ and $2^{\text {nd }}$ wave load matrix on the hull respectively, $\tilde{F}_{p}=$ transmitted force matrix from the interface, $\tilde{F}_{w}=$ wind loading, $\tilde{F}_{c}=$ current loading on hull, and $\tilde{F}_{W D}=$ wave drift damping force matrix.

\subsection{Numerical simulation}

Numerical simulations were carried out using the commercial software AQWA. The software is capable of analyzing floating platform responses using coupled dynamic analysis in either time or frequency domain. The 3D radiation/diffraction analysis was calculated for the hull hydrodynamics. The panel method was applied to compute the velocity potential using Green's function. For the analysis of mooring lines, AQWA adopts the discrete lumped mass method to calculate the line responses. The general process is depicted in Figure 1.

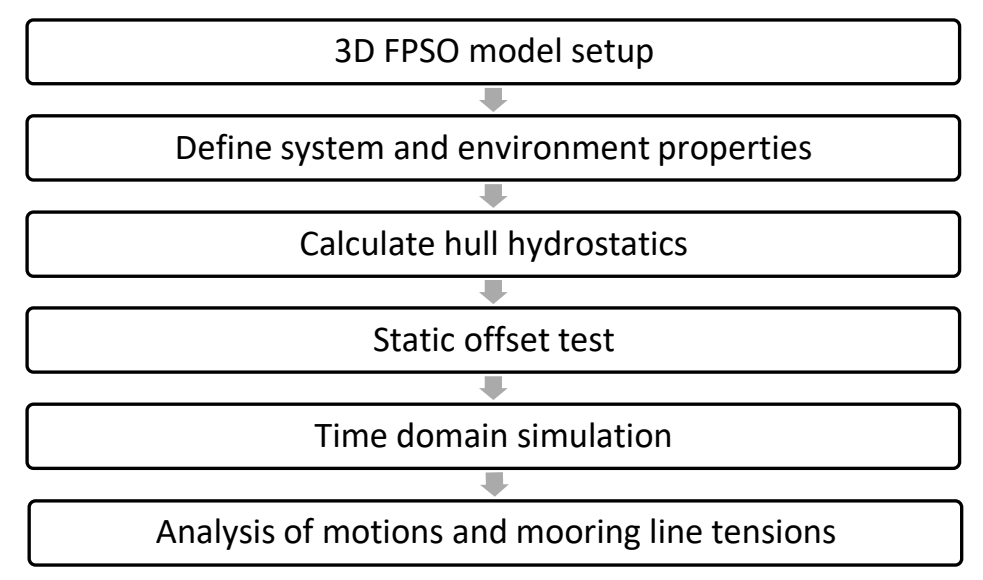

Fig. 1. Numerical simulation process.

A turret moored FPSO is considered for case study. The hull design is based on the model provided by Kim et al. [5], and is found in Table 1 in the Appendix.

The FPSO is connected to a mooring system composing of 12 lines in a $4 \times 3$ configuration. The arrangement of the lines is depicted in Figure 2. The lines in each group are spaced five degrees apart from the adjacent line, and the location radius of chain stoppers on the turret turntable is $7 \mathrm{~m}$. The general mooring line properties are found in Table 2. 


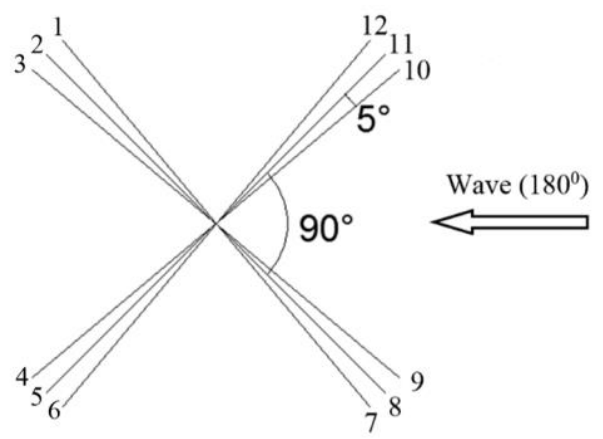

Fig. 2. Mooring arrangement.

In order to maintain the mooring lines inclination angle from the seabed to the turret as close as possible to the system at $2000 \mathrm{~m}$ depth for all cases, the systems with depths less than $2000 \mathrm{~m}$ were artificially "truncated" and adjusted to match the total horizontal restoring forces. A visualization on the steps taken to achieve the above requirement is shown in Figure 3, some as suggested by [8]: by adjusting mooring line segments' length, the extending the line length lying on the seabed, introducing clump weights and modifying the properties of the line lower segment. Table 3 provides the mooring line pretension and lengths of the segments suspended above the seabed in order to achieve the required state. Each line is composed of a combination of chain and polyester segments, with the top and bottom segment being chain and the middle segment as polyester.

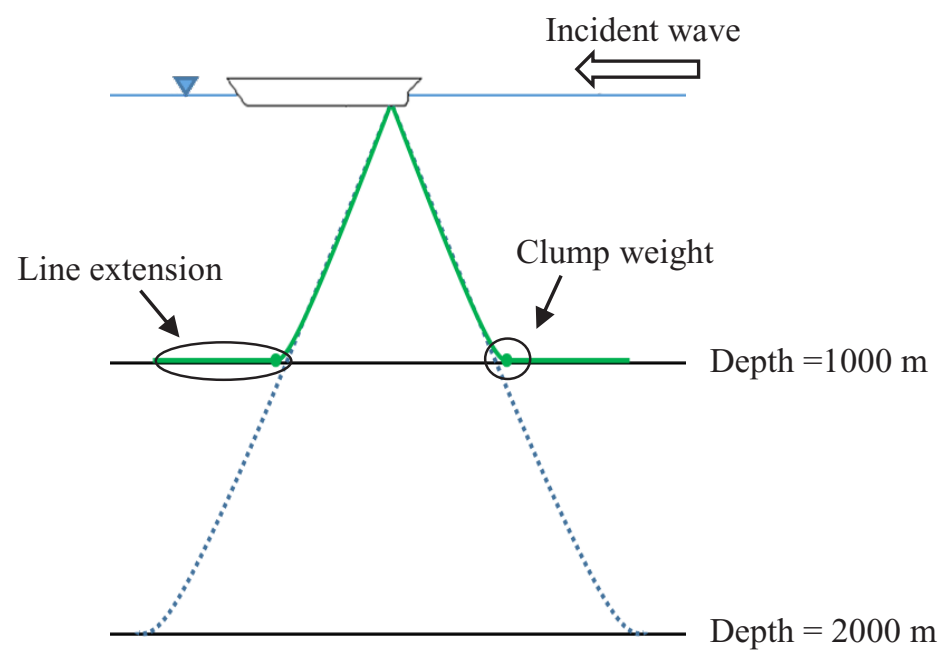

Fig. 3. Mooring line inclination (side view).

The FPSO system is subjected to a unidirectional wave condition shown in Table 4, propagating from the vessel bow (the end where the turret is located) to stern (see Figure 3). The JONSWAP spectrum model is used, given below:

$$
S(\omega)=\frac{\propto g^{2} \gamma^{a}}{\omega^{5}} \exp \left(-\frac{5 \omega_{p}^{4}}{4 \omega^{4}}\right)
$$


Where $\omega_{\mathrm{p}}=$ peak frequency, $\gamma=$ peak enhancement factor, and $\alpha=$ constant relating the wind speed and wave peak frequency.

Current and wind are not considered in this study.

\section{Results}

\subsection{Parametric study}

Analysis was carried out for water depths ranging from $1000 \mathrm{~m}$ to $2000 \mathrm{~m}$. All cases were simulated using coupled dynamic analyses, and were carried out in time domain.

\subsection{Static offset}

In order to maintain static equivalence for all cases during analysis, the static offset of each system was made to match as close as possible for all tested depths. Figure 4 shows the corresponding static offset results, which are relatively similar for all cases. In all cases, the systems showed a slight non-linear weakening in surge force due to the geometric nonlinearity of the catenary mooring lines.



Fig. 4. Surge static offset.

\subsection{Motions and mooring line tension}

The motions and mooring line tension data are presented below. Tables 5 to 9 show the data of the surge, heave, roll and pitch motions, as well as tension of the combined major loaded lines 7, 8 and 9. Figures 5, 7-10 shows the corresponding motion and line tension spectrum of the systems. On the other hand, Figures 6 and 11 plot the peak responses of the surge and line tension spectrum respectively. The sway and yaw are assumed to have minor effects on the weathervane FPSO in unidirectional wave, hence are not included in this study.

It can be seen from Figure 5 that the surge is LF dominated, and one can observe, from Figure 6, a general linear decrease in peak response as water depth increases. Increasing the water depth also resulted in decreasing maximum offset and standard deviation for surge (Table 5). Meanwhile, water depth is shown to have a minimal effect on the mean surge motion, with a variation of less than $1 \mathrm{~m}$ throughout all cases. It is noted in Figure 6 however, that the surge response experiences a sudden jump in the response at the $1500 \mathrm{~m}$ depth, before resuming its declining trend. 


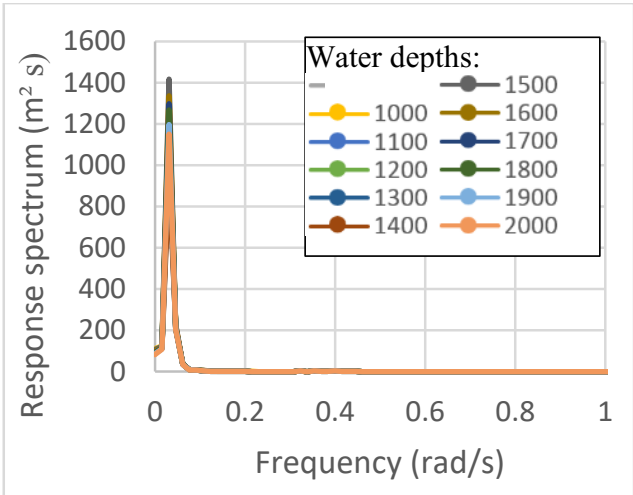

Fig. 5. Surge spectrum

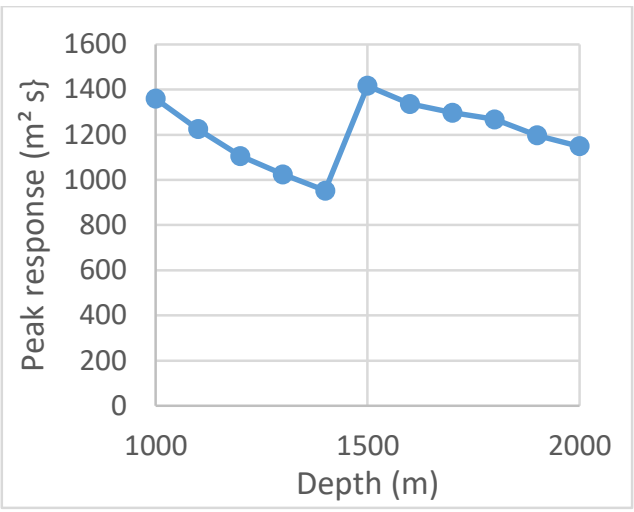

Fig. 6. Surge peak spectrum response.

For the heave, roll and pitch, the responses are wave frequency (WF) dominated, and no meaningful changes are observed by varying water depth (Figs. 7-9; Tables 6-8).

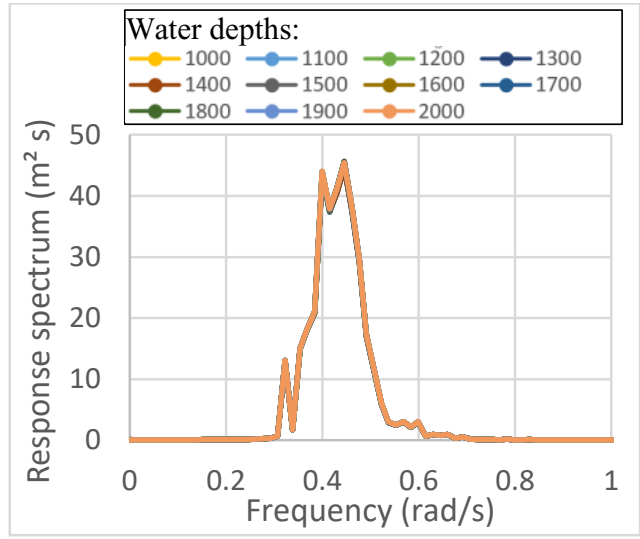

Fig. 7. Heave spectrum

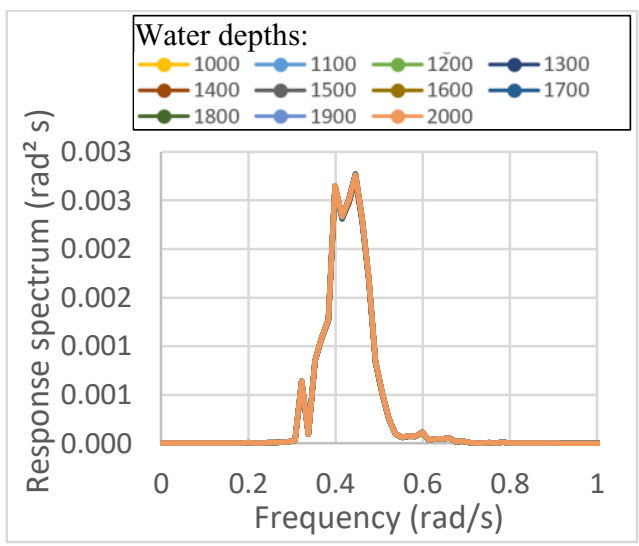

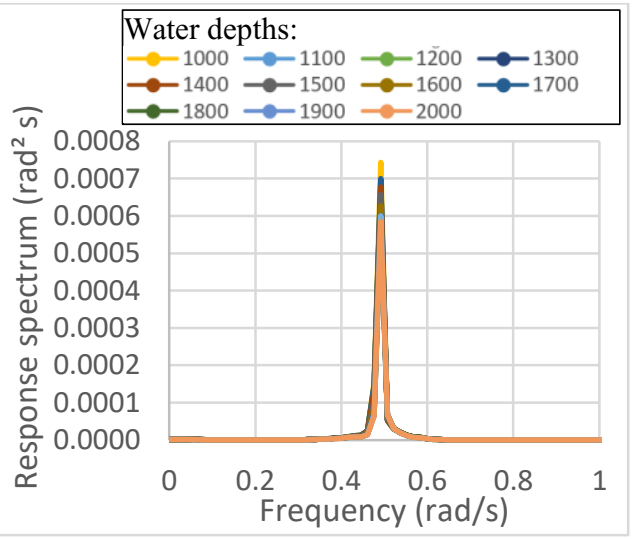

Fig. 8. Roll spectrum

Fig. 9. Pitch spectrum 
Concerning the major loaded mooring line tension, from Table 9 it is found that the mean value generally increases with increasing depth. The same is observed, although more erratically, for the maximum tension. Figure 11 shows that, for major loaded lines 7, 8 and 9 , the response decreases with increasing water depth. The trend is observed to be similar to that of the surge response. It is noted that the mooring line tension is largely dominated by LF responses as shown in Figure 10, while the effects of WF responses are minimal.

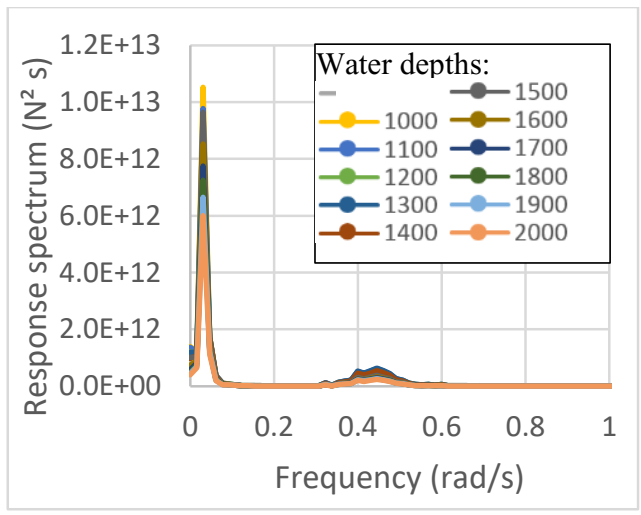

Fig. 10. Combined line tensions 7,8,9 spectrum spectrum response.



Fig. 11. Combined line tensions 7,8 ad 9 peak

From the analysis, it is clearly shown that the mooring system mainly defines the LF responses of a floating system. The hull itself has effectively little to no hydrostatic stiffness in the surge and sway, and thus the system is wholly reliant on the mooring lines for station keeping. This, coupled with the low mooring line damping, causes the natural period of the surge to be significantly larger compared to the peak wave period.

Additionally, the effects of the mooring line increases with increasing depth. As the water depth increases, the length of the line increases. Additional damping due to the mooring line drag and inertia becomes larger. In shallow waters where the line length is relatively short, these properties are small and can be; however, its influence increases at deeper waters. Thus, the mooring line damping plays a significant role in reducing the LF motions of a floating system in deepwater.

Consequently, as the mooring line forces in a turret-moored vessel is mainly dictated by the LF surge and sway, the response is naturally expected to follow that of the surge in this case.

Previously it is noted in Figures 6 and 11 that the responses experience a jump at the $1500 \mathrm{~m}$ depth. This is thought to be due mainly to the sudden increase in the mooring line pretension. The difference in pretension to the next analysed depth case is less than $8 \%$ until reaching $1400 \mathrm{~m}$. At $1500 \mathrm{~m}$, the pretension difference is $39 \%$, nearly five times greater than that of the previous cases. The difference is then reduced to not more than $20 \%$ for the subsequent cases up to $2000 \mathrm{~m}$.

In the floating system, the hydrostatic stiffness of the hull mainly influences the WF responses. The contribution of the mooring line stiffness is small compared to the hull itself. Due to the large hydrostatic stiffness of the FPSO, the natural period of heave, roll and pitch is short compared to the surge. Hence, WF responses of heave pitch and roll are independent of water depth.

In all cases, changes in water depth does not have an effect on the natural frequency of the system. 


\section{Conclusion}

A study is conducted to investigate the response of a floating FPSO system at depths ranging from $1000 \mathrm{~m}$ to $2000 \mathrm{~m}$, using coupled dynamic analysis. The system had previously been validated with an existing published study. Based on the results, the following conclusions can be drawn:

- The surge motion is governed by LF responses, and are mainly influenced by mooring line damping. As the water depth increases, the damping increases, and thereby reducing the surge response and maximum offset.

- Consequently, the mooring line tension spectrum response decreases as the depth increases, as the line tensions is directly affected by the LF motions, particularly the surge. The mean line tension however, increases with increasing depth.

- The WF responses heave, roll and pitch are primarily influenced by the hydrostatic stiffness of the floating hull, and are not affected by water depth.

The authors would like to thank the Ministry of Higher Education Malaysia (MOHE), to which the project was funded under the FRGS grant.

\section{References}

1. X. Chen, J. Zhang, W. Ma, Ocn. E., 28(7), 863-887 (2001)

2. X. Chen, Y. Ding, J. Zhang, P. Liagre, J. Niedzwecki, P. Teigen, Ocn. E., 33(1), 93117 (2006)

3. D. Qiao, J. Ou, 20th International Offshore and Polar Engineering Conference, (2010)

4. J. E. Gutiérrez-Romero, J. García-Espinosa, B. Serván-Camas, B. Zamora-Parra, Mar. Struct., 49, 116-137 (2016)

5. M.H. Kim, B.J. Koo, R.M. Mercier \& E.G. Ward, Ocn. E. J., 32, 1780-1802 (2005)

6. H. Ormberg, K. Larsen, Appl. Ocean Rsch., 20, 55-67 (1998)

7. M. Guan, M. Osman, C. Y. Ng, E3S Web of Conferences, 34, 8 (2018)

8. I. Fylling, C. Stansberg, Deep Oil Technology, (2005) 


\section{Appendix}

Table 1. FPSO details.

\begin{tabular}{|c|c|c|}
\hline Parameter & Units & Value \\
\hline Production level & bpd & 120000 \\
\hline Storage & bbls & 1440000 \\
\hline Vessel size & kDWT & 200 \\
\hline Length between perpendicular, Lpp & $\mathrm{m}$ & 310 \\
\hline Breadth & $\mathrm{m}$ & 47.17 \\
\hline Height & $\mathrm{m}$ & 28.04 \\
\hline Draft ( $80 \%$ loaded $)$ & $\mathrm{m}$ & 15.121 \\
\hline Displacement & MT & 186051 \\
\hline Surge centre of gravity from turret, CGx & $\mathrm{m}$ & -109.67 \\
\hline Heave centre of gravity from mean water level, CGx & $\mathrm{m}$ & -1.8 \\
\hline Frontal wind area & $\mathrm{m}^{2}$ & 4209.6 \\
\hline Transverse wind area & $\mathrm{m}^{2}$ & 16018.6 \\
\hline Roll radius of gyration at $\mathrm{CG}, \mathrm{Rxx}$ & $\mathrm{m}$ & 14.036 \\
\hline Sway radius of gyration at CG, Ryy & $\mathrm{m}$ & 77.47 \\
\hline Yaw radius of gyration at $\mathrm{CG}, \mathrm{Rzz}$ & $\mathrm{m}$ & 79.3 \\
\hline Turret in center line behind Fpp & $\mathrm{m}$ & 38.75 \\
\hline Turret diameter & $\mathrm{m}$ & 15.85 \\
\hline
\end{tabular}

Table 2. Mooring line details.

\begin{tabular}{|c|c|c|c|}
\hline Parameter & Units & Chain & Polyester \\
\hline Mass per unit length & $\mathrm{kg} / \mathrm{m}$ & 189.2 & 16.7 \\
\hline Diameter & $\mathrm{mm}$ & 95.3 & 160 \\
\hline Stiffness, EA & $\mathrm{kN}$ & 820900 & 187000 \\
\hline Normal drag coefficient, $\mathrm{C}_{\mathrm{DN}}$ & - & 2.45 & 1.2 \\
\hline Normal added inertia coefficient, $\mathrm{CIN}_{\mathrm{N}}$ & - & 2 & 1.1 \\
\hline
\end{tabular}


Table 3. Individual mooring line properties.

\begin{tabular}{|c|c|c|c|c|}
\hline \multirow{2}{*}{ Depth (m) } & \multirow{2}{*}{$\begin{array}{c}\text { Pretention } \\
(\mathbf{k N})\end{array}$} & \multicolumn{3}{|c|}{ Line segment (m) } \\
\cline { 3 - 5 } & 103 & 10 & 120 & - \\
\hline 100 & 589 & 121.9 & 1327.5 & - \\
\hline 1000 & 585 & 121.9 & 1474.6 & - \\
\hline 1100 & 612 & 121.9 & 1621 & - \\
\hline 1200 & 601 & 121.9 & 1758.25 & 10 \\
\hline 1300 & 644 & 121.9 & 1893.9 & 20 \\
\hline 1400 & 896 & 121.9 & 1968 & 90.25 \\
\hline 1500 & 1078 & 121.9 & 2092.5 & 110 \\
\hline 1600 & 1283 & 121.9 & 2216.25 & 130 \\
\hline 1700 & 1397 & 121.9 & 2360.5 & 130 \\
\hline 1800 & 1330 & 121.9 & 2487 & 150 \\
\hline 1900 & 1429 & 121.9 & 2689.4 & 91.4 \\
\hline 2000 & & & & \\
\hline
\end{tabular}

Table 4. Environmental condition.

\begin{tabular}{|c|c|c|}
\hline Parameter & Units & Value \\
\hline Water depth & $\mathrm{m}$ & 1829 \\
\hline \multicolumn{2}{|c|}{ Wave } & 12.19 \\
\hline Significant wave height, $\mathrm{H}_{\mathrm{s}}$ & $\mathrm{m}$ & 14 \\
\hline Peak period, $\mathrm{T}_{\mathrm{p}}$ & $\mathrm{s}$ & - \\
\hline Spectrum & JONSWAP & 2.5 \\
\hline Peak factor, $\gamma$ & - & 180 \\
\hline Direction & degree & \\
\hline
\end{tabular}


Table 5. Surge statistical results.

\begin{tabular}{|c|c|c|c|c|c|c|}
\hline Depth & $\mathbf{1 0 0 0}$ & $\mathbf{1 1 0 0}$ & $\mathbf{1 2 0 0}$ & $\mathbf{1 3 0 0}$ & $\mathbf{1 4 0 0}$ & $\mathbf{1 5 0 0}$ \\
\hline Max (m) & 126.95 & 126.50 & 126.31 & 125.88 & 125.87 & 126.89 \\
\hline Min (m) & 95.71 & 96.01 & 95.96 & 96.07 & 96.07 & 96.15 \\
\hline Mean (m) & 111.62 & 111.63 & 111.68 & 111.60 & 111.74 & 111.65 \\
\hline Std. dev. (m) & 5.33 & 5.13 & 4.95 & 4.80 & 4.71 & 5.40 \\
\hline Depth & $\mathbf{1 6 0 0}$ & $\mathbf{1 7 0 0}$ & $\mathbf{1 8 0 0}$ & $\mathbf{1 9 0 0}$ & $\mathbf{2 0 0 0}$ & \\
\hline Max (m) & 126.76 & 126.54 & 126.47 & 126.23 & 125.85 & \\
\hline Min (m) & 96.34 & 96.61 & 96.72 & 96.90 & 97.17 & \\
\hline Mean (m) & 111.71 & 111.72 & 111.75 & 111.77 & 111.74 & \\
\hline Std. dev. (m) & 5.28 & 5.21 & 5.16 & 5.05 & 4.96 & \\
\hline
\end{tabular}

Table 6. Heave statistical results.

\begin{tabular}{|c|c|c|c|c|c|c|}
\hline Depth & $\mathbf{1 0 0 0}$ & $\mathbf{1 1 0 0}$ & $\mathbf{1 2 0 0}$ & $\mathbf{1 3 0 0}$ & $\mathbf{1 4 0 0}$ & $\mathbf{1 5 0 0}$ \\
\hline Max (m) & 6.41 & 6.40 & 6.40 & 6.39 & 6.40 & 6.37 \\
\hline Min (m) & -11.62 & -11.59 & -11.60 & -11.59 & -11.61 & -11.65 \\
\hline Mean (m) & -1.89 & -1.89 & -1.89 & -1.89 & -1.90 & -1.94 \\
\hline Std. dev. (m) & 2.35 & 2.34 & 2.34 & 2.34 & 2.35 & 2.36 \\
\hline Depth & $\mathbf{1 6 0 0}$ & $\mathbf{1 7 0 0}$ & $\mathbf{1 8 0 0}$ & $\mathbf{1 9 0 0}$ & $\mathbf{2 0 0 0}$ & \\
\hline Max (m) & 6.34 & 6.30 & 6.29 & 6.30 & 6.29 & \\
\hline Min (m) & -11.69 & -11.72 & -11.74 & -11.73 & -11.75 & \\
\hline Mean (m) & -1.98 & -2.01 & -2.03 & -2.02 & -2.03 & \\
\cline { 1 - 5 } Std. dev. (m) & 2.36 & 2.36 & 2.36 & 2.36 & 2.36 & \\
\cline { 1 - 4 } & & &
\end{tabular}


Table 7. Roll statistical results.

\begin{tabular}{|c|c|c|c|c|c|c|}
\hline Depth & $\mathbf{1 0 0 0}$ & $\mathbf{1 1 0 0}$ & $\mathbf{1 2 0 0}$ & $\mathbf{1 3 0 0}$ & $\mathbf{1 4 0 0}$ & $\mathbf{1 5 0 0}$ \\
\hline Max (rad) & 0.0167 & 0.0158 & 0.0158 & 0.0159 & 0.0156 & 0.0164 \\
\hline Min (rad) & -0.0168 & -0.0156 & -0.0153 & -0.0153 & -0.0149 & -0.0169 \\
\hline Mean (rad) & 0.0002 & 0.0002 & 0.0002 & 0.0002 & 0.0002 & 0.0002 \\
\hline Std. dev. (rad) & 0.0042 & 0.0041 & 0.0041 & 0.0041 & 0.0040 & 0.0039 \\
\hline Depth & $\mathbf{1 6 0 0}$ & $\mathbf{1 7 0 0}$ & $\mathbf{1 8 0 0}$ & $\mathbf{1 9 0 0}$ & $\mathbf{2 0 0 0}$ & \\
\hline Max (rad) & 0.0157 & 0.0151 & 0.0145 & 0.0140 & 0.0142 & \\
\hline Min (rad) & -0.0162 & -0.0157 & -0.0150 & -0.0145 & -0.0139 & \\
\hline Mean (rad) & 0.0002 & 0.0002 & 0.0002 & 0.0002 & 0.0002 & \\
\cline { 1 - 5 } Std. dev. (rad) & 0.0038 & 0.0037 & 0.0037 & 0.0037 & 0.0037 & \\
\hline
\end{tabular}

Table 8. Pitch statistical results.

\begin{tabular}{|c|c|c|c|c|c|c|}
\hline Depth & $\mathbf{1 0 0 0}$ & $\mathbf{1 1 0 0}$ & $\mathbf{1 2 0 0}$ & $\mathbf{1 3 0 0}$ & $\mathbf{1 4 0 0}$ & $\mathbf{1 5 0 0}$ \\
\hline Max (rad) & 0.07422 & 0.07409 & 0.0741 & 0.0741 & 0.0742 & 0.0744 \\
\hline Min (rad) & -0.0643 & -0.0643 & -0.0643 & -0.0642 & -0.0643 & -0.0640 \\
\hline Mean (rad) & 0.0019 & 0.0019 & 0.0020 & 0.0019 & 0.0020 & 0.0023 \\
\hline Std. dev. (rad) & 0.0178 & 0.0177 & 0.0177 & 0.0177 & 0.0178 & 0.0178 \\
\hline Depth & $\mathbf{1 6 0 0}$ & $\mathbf{1 7 0 0}$ & $\mathbf{1 8 0 0}$ & $\mathbf{1 9 0 0}$ & $\mathbf{2 0 0 0}$ & \\
\hline Max (rad) & 0.0746 & 0.0748 & 0.0750 & 0.0749 & 0.0750 & \\
\hline Min (rad) & -0.0639 & -0.0636 & -0.0635 & -0.0637 & -0.0636 & \\
\cline { 1 - 5 } Mean (rad) & 0.0024 & 0.0027 & 0.0028 & 0.0027 & 0.0028 & \\
\hline Std. dev. (rad) & 0.0178 & 0.0178 & 0.0178 & 0.0178 & 0.0179 & \\
\hline
\end{tabular}


Table 9. Statistical results of combined line tensions 7,8,9.

\begin{tabular}{|c|c|c|c|c|c|c|}
\hline Depth & 1000 & 1100 & 1200 & 1300 & 1400 & 1500 \\
\hline $\operatorname{Max}(\mathrm{kN})$ & 5072.1 & 5060.0 & 5077.0 & 5095.4 & 5125.0 & 5673.5 \\
\hline $\operatorname{Min}(\mathrm{kN})$ & 520.0 & 436.9 & 498.3 & 499.4 & 633.8 & 1635.4 \\
\hline Mean $(\mathrm{kN})$ & 2380.3 & 2370.0 & 2434.5 & 2408.0 & 2562.8 & 3249.1 \\
\hline Std. dev. (kN) & 757.8 & 755.8 & 727.4 & 722.9 & 683.0 & 698.3 \\
\hline Depth & 1600 & 1700 & 1800 & 1900 & 2000 & \\
\hline $\operatorname{Max}(\mathrm{kN})$ & 6006.8 & 6445.3 & 6655.9 & 6356.1 & 6526.6 & \\
\hline $\operatorname{Min}(\mathrm{kN})$ & 2116.8 & 2705.0 & 3019.1 & 2772.1 & 3098.3 & \\
\hline Mean $(\mathrm{kN})$ & 3757.2 & 4340.0 & 4659.8 & 4448.0 & 4728.2 & \\
\hline Std. dev. (kN) & 658.5 & 627.3 & 607.0 & 588.1 & 560.5 & \\
\hline
\end{tabular}

